\title{
The Mythical Fall and Don DeLillo's Falling Man: Mediations on Narratives of Violence and Human Rights
}

\author{
Debopriya Banerjee \\ Post-doctoral Fellow, IISER Bhopal, M.P. Email: debopriya83@gmail.com
}

\begin{abstract}
The spectacular impact of the fall of the twin towers of the World Trade Center on Septemberil, 2001, was felt in a wide variety of domains trying to grapple the political, literal, and figural ruins and reformulating a post-Holocaust trauma and memory studies. While the experience and representations of trauma have always been a potential site for the interface between the tenets of human dignity, justice and literary text, this incident has also brought to the fore the radical embodied politics of suicide missions. Drawing insights from the contemporary studies of human rights which focus on the paradoxical erasure of embodied human experience, this article explores how Don DeLillo's novel Falling Man fictionalizes the conflicting embodied experience of the victim and the aggressor against the colossal visual impact of the fall of the towers.
\end{abstract}

Keywords: 9/11 and literature, embodiment, trauma, human rights, spectacle

\section{Introduction}

In her introduction to Fictions of Dignity: Embodying Human Rights in World Literature Elizabeth Anker astutely diagnoses two central paradoxes as the often overlooked malaise that mar the ethical imperatives behind idiom of human rights: the obliteration of the human body and the exclusion of certain human communities within the normative valorization of human dignity (Anker, 2012). Recent studies in the area also reveal how these set of secular religious formations are mired in multiple paradoxes. From the paradox of legitimate warfare and terrorism, to those of citizenship and testimonial witness, every single tenet of human dignity is riddled in paradox. Goldberg and Moore's expansive list enumerates how these inherent paradoxes weaken the supposed efficacy of human rights (Goldberg \& Moore, 2012). Focusing on the paradoxical "ambivalence toward embodiment" Anker notes that the foundations of dignity and bodily integrity somewhat naively rest on a notion of human self severed from the corporeality of the human body: "Not only are they [human rights] underwritten by the dual fictions of the human dignity and bodily integrity, but they yield a highly truncated, decorporealised version of the subject - one that paradoxically negates core dimensions of embodied experience" (Anker, 2012, p.2). If a certain erasure of the "fleshliness", constitutes the contours of the human self in human rights, the other more predictable paradox is the surreptitious Euro-American colonization of the idiom of justice. This semantic colonization eventually leads to an exclusion of the complex

(c) AesthetixMS 2019. This Open Access article is published under a Creative Commons Attribution Non-Commercial 4.0 International License (http://creativecommons.org/licenses/by-nc/4.o/), which permits non-commercial re-use, distribution, and reproduction in any medium, provided the original work is properly cited. For citation use the DOI. For commercial re-use, please contact editor@rupkatha.com. 
human experience in the post colony. Needless to say the normative demands of dignity and equality are almost always orchestrated along the established lines of geopolitical and cultural hierarchies.

Essentially then Anker's critical intervention zeroes on two fundamental erasure: the corporeal subject within the Euro-American context, and collective life residing beyond the EuroAmerican domain. She resorts to a host of literary narratives gleaned from across cultures of violence to salvage the profound disservice done to embodied experience. Anker's efforts to restore embodied experience is of particular significance within the ever-expanding paradigm of trauma and memory studies that emerged in the aftermath of the suicide attacks on the World Trade Center on September 11, 2001. Certainly the association of trauma and witnessing with the therapeutic value of literary and visual art is not new. Trauma and narratives about trauma have always been an important analytic to study the interface between violence, human dignity and literature. But the attack on the World Trade Center has also brought to the fore the less visible embodied politics of self-annihilating mission. This article intends to study Don DeLillo's Falling Man to explore how the dominant Euro-American fictional aftertext straddles two precariously intertwined notions of embodied selfhood: the victim who experiences traumatic aftershocks inflicted by the aggressor who uses the body, or rather paradoxically the annihilation of the body to enact an individuation not acknowledged in what Anker terms "the liberal cartography of selfhood" (2012, p.5). Written against a backdrop of the spectacular fall, the novel juxtaposes the opposing experiences of a survivor, and a fictional suicide bomber. The sustained intertexual presence of the iconic photograph of the falling man adds yet another dimension to the text. It invokes the duality of lived experiences of suffering and the photo journalism of spectacle, trauma and devastation. In this sense the novel can also be read as a response to a question Rey Chow aptly broaches in the context of the atomic explosion in Hiroshima and Nagasaki. At a time when the world is increasingly grasped and conceived as a picture, what possible contribution, Chow asks, can modern self-referential writing make in the expanding narrative of human atrocity and suffering? (Chow, 2006, p.12).

\section{The Weight of Words, the Shock of a Photograph}

Even though conflicting narratives of embodied suffering lie at the heart of " $9 / 11$ ", if the almost dizzying number of response are to be an indicator, the post-9/11 discursive canon navigates the economy of spectacle and the vast inchoate maze of individual/collective testimonial accounts. The aftermath of $9 / 11$ is primarily preoccupied with the authentic act of witnessing, and belated public representations of it. The private act of witnessing and the public representations are a reappraisal of the notional unspeakability of trauma configured in Cathy Caruth's seminal work on trauma, memory and representation. Caruth's pioneering volume on the subject suggests that an occurrence of this magnitude ultimately remains beyond the pale of representation irrespective of the quantum of testimonial data. Cathy Caruth's formulations which are anchored around the Holocaust (and the atomic explosion to a lesser extent) locate an occurrence of trauma ultimately beyond the representational domain (Caruth, 1996). Goldberg and Moore's reading of Carolyn Forche's The Angel of History also resonate with the fundamental paradox of recording the unrepresentable: "If you want, I'll tell you, but nothing I say will be enough" (Goldberg \& Moore, 2013, p.19). Both Marianne Hirsch and Ulrich Baer in their works on the photographs of Holocaust do not deviate from Caruth's defining premise of trauma as a gap or a block in memory that elides representation. As Baer puts it, a traumatic catastrophe is ultimately "a disorder of memory and time" (Baer, 2002, p.9). As I will elaborate later, Baer's insights on 
trauma and photographs of trauma assess how, if at all, photographs can reconcile this delinking of seeing and knowing. But occurring at a time of hyper-visual media culture and grounded in an altered context and method of conflict/resistance, 9/11 has nonetheless triggered an entirely different grammar of embodied suffering, dignity and witnessing. The multiple aspects of this incident complicate and rather far exceed the existing framework of experiencing, witnessing and recording the inexhaustible extremity.

Noting the mutual affinity that human rights and literature have for paradoxes, Goldberg and Moore remind that for litterateurs and readers alike what matter is the space at the heart of paradox where two contradictory ideas collide but never coincide. Falling Man which is an appropriate sample from the vast, disparate fictional responses to $9 / 11$ narrates conflicting embodied experiences colliding in that one spectacular epistemic instant: the eponymous falling man inspired from Richard Drew's famous photograph of a man jumping from the World Trade Center, a survivor and a fictional terrorist assigned to navigate the aircraft. The novel also incorporates a performing artist who enacts the fall at different locations of the city using rudimentary equipment. Falling Man opens a few minutes after the explosion following the exit of the survivor, Keith Neudecker who witnesses a man falling from one of the towers. Keith's subsequent emotional restitution forms the narrative praxis of the novel. Along with Keith Neudecker's almost inescapable confrontation with the moment of the collapse of the towers even in the aftermath, the novel also incorporates the private anguish of a host of other characters trying to script their own narrative of the fall. These subsidiary clusters of characters resort to televised footage and other visual simulation mechanism to re-claim and internalize an experience they have not witnessed first-hand. Juxtaposed against the survivors' arduous search for a narrative of their own is the fictional terrorist Hammad's preparation for the suicide mission during the days and months leading to the moment. The elliptical narrative structure begins as well as ends with the moment of extremity slowly unfolding. Such a scheme then allows the author not just to ponder the central paradox of "how" to write the unspeakable in retrospect; it also enables him to engage with conflicting narratives of embodied experience alongside the larger economy of spectacle and simulation. By offering a close but partial look into Falling Man I intend to explore this burgeoning paradox - the hyper-visible moment of extremity, the lived experience of suffering and the embodied dissent of the aggressor. I argue that despite DeLillo's inclusion of divergent kinds of lived experience and multiple modes of witnessing, the novel unambiguously tilts in favor of the overarching allegory of the mythical fall. The testimonial imprints of suffering are eventually morphed into the colossal image of falling, somehow muffling the discordant note of the aggressor's embodied dissent. In doing so it writes the fictional terrorist and his bodily dissent as a nihilistic act of a dispossessed individual.

Critical responses to the novel (barring a few) have been more than generous. Georgiana Banita among others lauds the novelist for resisting a supposed voyeuristic obsession with this unfolding scene of postmodern sublime. Banita's appraisal of Falling Man is an important point of reference, for the premise of her book appropriately titled Plotting Justice addresses the interface of literature and ethical aesthetics. Her argumentative proposition rests on DeLillo's craftsmanship in churning a narrative resistant to ideological closure, favoring instead a pluralist ethical spectatorship and empathetic (but not affective) engagement with suffering. (Banita, 2012). Banita notes that DeLillo avoids both the affective culture of emotional overload, or an unquestionable allegiance to stock images of suffering by introducing various dispassionate styles of seeing that do not fall within the predictable moral lexicon. She writes: "Falling Man fastidiously describes the characters' individual perception of what they see, whether as direct witness or through intermediary visual artifacts. The image of a WTC jumper is central among 
these" (Banita, 2012, p.64). The novel opens seconds after the collapse of the first tower. Keith Neudecker, the central witness, and an embodied extension of the WTC jumper emerges from one of the towers into the infantile urban dystopia that New York has metamorphosed into. DeLillo's narratorial voice, like a dexterous lens pans around creating a photomontage of New York street life after the fall:

"[i]t was not a street anymore, but a world, a time and space of falling ash, and near night" [...] "the world was this as well, figures in windows a thousand feet up, dropping into free space, and the stink of fuel fire, and the steady rip of sirens in the air. The noise lay everywhere they ran, stratified sound collecting around them, and he walked away from it and into it at the same time" (DeLillo, 2008, p.1).

The opening pages continue in shorter paragraphs as if keeping pace with Keith's slow and somewhat befuddled movement along the road with "glass in his hair and face, marbled balls of blood and light" (DeLillo, 2008, p.1). These shorter paragraphs record apparently the mind's assemblage of what the eyes witness - vignettes of human debris against a vast void:

"There was something critically missing from the things around him. They were unfinished, whatever that means. They were unseen, whatever that means, shop windows, loading platforms, paint-sprayed walls. May be this is what it looks like when there is no one here to watch them" (DeLillo, 2008, p.1).

Within this ruin in making, Keith finally witnesses the free fall of the WTC jumper:

"There was something else then, outside all this, not belonging to this, aloft. He watched it coming down. A shirt came coming down out of the high smoke, a shirt lifted and drifting in the scant light and then falling again, down toward the river" (DeLillo, 2008, p.4).

Georgiana Banita particularly lauds DeLillo's method of using Richard Drew's famous photograph, and yet simultaneously substituting it with a shirt. This shift from the man in flight to a shirt gliding downwards delineates a "surreally decelerated movement [...] the slowness of the shirt's descent offers a more palatable alternative to the fall of a living person, whose life would have been terminated within a matter of seconds" (Banita, 2012, p.65). The descent of the shirt resists the definitive termination of a man's life and implicitly suggests "a continued presence within the reader's imagination" (Banita, 2012, p.65).

DeLillo's stylized version of the WTC jumper and Banita's critical appraisal however open a minefield of ethico-aesthetic (and political) problem of reading photographic documents of embodied suffering. Responses to Drew's photograph, (which Banita only passingly alludes to) amply demonstrate the rather precarious relation between photography of trauma and ethical spectatorship. Even though photographs have always been a principal mode of representing the traumatic, the conflicting avowal and disavowal of this photograph alone reveal the perilous intersection of trauma and the act of witnessing. For many the graceful flight of a person is an aesthetic subject intended to be perceived more as an artifact than a historical evidence of individual death. Conversely the same photograph can also be read as an authentic document of embodied suffering. Alongside the hyperbolic televised footage of the crumbling towers, this photograph is an astounding statement on the horror of embodied suffering. Yet, the freeze frame of the body in downward motion also stalls the invariability of death, performing a justice only photographic art is capable of accomplishing. Banita invokes Susan Lurie and Barbie Zelizer who read this photograph as a piece of speculative document, an open ended text that demonstrates the power of camera to encapsulate a traumatic extremity of suffering and yet halt the inevitable destruction (Banita, 2012, p.6). Lurie and Zelizer point to a distinct photographic temporality that 
arrests a moment and yet manages to avert the invariable future that moment entails. Their observations on this unique ability of photographic temporality falls in line with Ulrich Baer's reading of photography that capture the "shrapnel of traumatic time" (Baer, 2002, p.7). Ulrich Baer, following the psychoanalytic approach of Caruth defines trauma as a disjuncture, as a break in the mind's experience of time, a wound that was experienced too soon to be known fully. Referring to the photographs of Holocaust Baer argues that the photographs of trauma do not simply index this crisis of referentiality, they also precipitate it. Both photography and trauma enact the disjunction of seeing and knowing: "because trauma blocks routine mental processes from converting an experience into memory or forgetting, it parallels the defining structure of photography, which also traps an event during its occurrence while blocking its transformation into memory" (Baer, 2002, p.9). The freeze frames of Holocaust, Baer insists, do not document a historical context. They do not transmit some kind of immutable ethical truth quotient. Yet their redemptive power lie in their being so open ended, in their ability to stir the imagination of the viewer. They become a medium of "salvaging, preservation and rescue of reality [....] precisely because photographs do appear immutable, we carry the burden of imagining what could occur beyond the boundaries of print" (Baer, 2002, p.24; emphasis in original). By shifting the onus of responsibility to the imagination of the viewer Baer seems to suggest that viewing is not a passive optical activity. The meaning of a photograph does not reside in its immediate historical context, but in imaginative and responsible viewing, capable of exploring "a history still unknown because it was experienced as traumatic" (Baer, 2002, p.22).

While Baer's project builds a strong case for individual ethical spectatorship, it also implicitly entails the consequence of a moment of trauma held hostage by an aggressive media culture, and political machinery. Susan Sontag blatantly situates the ethics of viewing not in the empathetic imagination of the individual mind, but in the regulatory mechanism of contemporary media and politics. In a world deeply marked by inequality, every hyper-visible metonymy of violence is also a reminder to ask "what pictures, whose cruelties, whose deaths are not being shown" (Sontag, 2003; emphasis in original). The ultra-celebrated, ultra-familiar shock photograph works more as a quotation, a maxim, or a proverb subject to instant recall. Within the limited framework of DeLillo's fiction or the broader space of American national imaginary the "falling man" is not so much about an individual experience of suffering or imaginative viewing. The graceful flight of a person has been over the years the locus of a master narrative of collective suffering of a nation in the aftermath of $9 / 11$. As is self-evident such a narrative invariably operates on the exclusion of other narratives of suffering and manufactures mass consent and sympathy. Roland Barthes' comments on visual texts elucidate the insidious manner in which a particular visual narrative of injustice is valorized and legitimized. Such photojournalism of suffering, Barthes observes, denies the onlooker her critical ability to judge, leaving her with a "simple right of intellectual acquiescence" (Banita, 2012, p.71). The compliant narrative of DeLillo uses this image just as Sontag diagnoses: a quotation or a maxim subject to repeated recall. It displaces the materiality of suffering only to provide a topoi of collective suffering and mourning. DeLillo's aesthetic stylization of the falling man witnessed by Keith works to elicit an intellectual consent from readers and stops deliberately short of fictionalizing a vast historical continuum of human suffering that exists beyond the domain of this image or the topographical limits of the nation.

The function of the street performer dubbed as the "falling man" within the narrative is also quite similar. The multiple performances of the fall reinforce the allegorical horror and recreate a collective dread. The street performer enacts/simulates the falling man from the towers in different parts of the city using rudimentary equipment but eventually dies of a heart ailment. 
These are subsidiary simulation mechanism intended to be viewed by those other than Keith, the only witness to the event. When Lianne notices him for the first time, it dawns on her that:

"he brought it back, of course, those stark moments in the burning towers, when people fell or were forced to jump [...] It held the gaze of the world, she thought. There was the awful openness of it, something we'd not seen, the single falling figure that trails a collective dread, body come down among us all" (DeLillo, 2008, p.33; emphasis added).

Lianne witnesses another such street performance beside a railroad and realizes that passengers in a moving train will hardly be aware of the harness that the artist is using and for them it will be a fragment of reality that conceals its own fictional origin. The novel progresses mostly as disparate performances of this massive fall - real, recollected and simulated concluding very much the same way it began:

"they came out onto the street, looking back both towers burning and soon they heard a high drumming rumble and saw smoke rolling down from the top of one tower, billowing out ....then he saw a shirt come down out of the sky. He walked and saw it fall, arms waving like nothing in this life". (DeLillo, 2008, p.246; emphasis added)

This self-indulgent reliance on the image (and performance) of falling helps create what post-9/11 novel is primarily accused of: a visually gripping postmodern sublime. Against the panorama of this spectacular fall, DeLillo weaves a mini narrative of domestic discord and subsequent healing, each acting as the metaphor of the other. A distinctive feature of the novelistic responses to $9 / 11$ is the persistence use of domestic jeopardy, and an uncritical, affective American self-reference (Anker, 2011, p.464). The relocation of suffering within the confines of the home induces a historical forgetting of counter narratives of suffering. It is no coincidence that the central image of the falling man in the opening chapter is followed by Lianne's reminiscence of the sexually energized early years of her marriage with Keith. Lianne muses: "it was'nt just those days and nights in bed, sex was everywhere at first, in words, phrases, half gestures, the simplest intimation of altered space" (DeLillo, 2008, p.2). Their long separation ends with Keith standing on her doorway covered in soot and blood. Lianne accompanies him to the hospital, "step by step, like walking a child" (DeLillo, 2008, p.9). Keith and Lianne's benumbed suffering and subsequent baby steps towards recuperation anticipate and emulate the mutilated body politic confronting a shock that it fails or rather is too reluctant to decipher.

\section{Embodied Dissent and Human Rights}

The family unit of Keith Neudecker witnessing and coping with the dystopia-in-making forms a prototype of the American social-familial macrocosm. The solitary, dislocated mindscape of Hammad, the fictional terrorist, is juxtaposed against this familial-national universe. Assigned with the task of commandeering the aircraft this unthinking fundamentalist calmly inches towards the moment. For Hammad it will somehow bring a closure to the overwhelming solitude that he has been enduring all his life. While others in the novel are engaged with the act of "seeing" the fall, for Hammad, it is quite the reverse. The dispassionate loner feel the "magnetic effect of the plot...plot closed the world to the slenderest line of sight, where everything converges to a point" (DeLillo, 2008, p.174).

While an entire ambit of political rhetoric, transnational warfare and cultural artifacts formed around the emblematic fall and bruised bodies - a metaphorical extension of the wounded body politic - the suicide mission was quite predictably relegated to a domain of non- 
seeing and irrationality bordering on madness. The dominant Euro-American tendency to conceive suicide mission as a pathological communication dissonance is itself an evidentiary proof of the lacuna I referred to right at the outset. Challenging this restricted and evasive view Gayatri Spivak conceives suicide missions as "a message inscribed in the body, when no other means will get through" (Spivak, 2004). For her, the embodied act that willed the spectacle into existence was resistance writ large on the naked body. It is a terrorizing return to a naked lived experience of the dissimulated real when nothing else works. In a similar vein Nouri Gana in her incisive reading of Paradise Now, a film on the Palestinian question in particular and suicide missions in general observes that (even at the risk of courting controversy) self-annihilating missions are paradoxically the only method to speak and to narrativise the otherwise despicable and disposable identity. She says:

"a contested identity is essentially an identity forced not only to despise itself, but also, and whenever possible, to reduce itself to (the status of) nonexistence, or at least, of disposability - to liquidate or annihilate itself. A contested identity is, above all, an identity that is usurped from the otherwise inalienable right to re-present, assert and liberate itself - that is in many ways, to narrativize itself" (Gana, 2008, p.22).

A suicide mission is a paradoxical process of decomposition only to humanize oneself, a radical and defiant aporia within the human rights imaginary, the space at the heart of a paradox. This deliberate destruction of the body is a response to the "semantic colonization" of the tenets of suffering, justice and equality (Anker, 2012, p.2). Hence a metonymic bundling of suicide missions, terrorism, and pathological communication dissonance may not be an adequate apparatus to map the individual psyche of a dissenter or a brand of terrorism that $9 / 11$ has so gratuitously spawned.

Gana's article also broaches a crucial problematic in understanding and addressing missions like these. She rues that any attempt to understand a dissidence/resistance like selfdestructive violence contains an inevitable lurking fear of being perceived as a sympathizer of terrorist activity. One has to also confront the sheer methodological inadequacy when one aims to understand this particular form of dissidence not in terms of the purely ocular, the physical or the spectacular. The very purpose of a body strapped with explosives or other self-destructive mechanism is to radically counter the lingo of the hyper-visual media culture and project a kind of paradoxical invincibility that cannot be easily interpreted. Gana points out the need to read (and not see) it as a narrative within a larger historical continuum of struggle and conflict but underscores the sheer absence of an alternate interpretative framework (Gana, 2008). DeLillo's narrative principle chimes with this methodological inadequacy in narrating the human agency singularly as a manifestation of a self-imposed alienation. The suicide mission on the level of the text operates as a closure to the vast nothingness of Hammad's life: "he is not thinking again, looking past the face in the mirror, which is not his, and waiting for the day to come, clear skies, light winds, when there is nothing left to think about" (DeLillo, 2008, p.178)

\section{Conclusion}

Early in the novel when Keith goes for a medical treatment, the doctors while removing splinters of glass out of his face inform that in incidents of suicide bombing survivors tend to develop "bumps, for lack of a better term, and it turns out this is caused by small fragments, tiny fragments of the suicide bombers body" (DeLillo, 2008, p.16). The body of the bomber gets blown to pieces and fragments of his body, little pellets of flesh flying at a high velocity are trapped in 
the body of a survivor nearby. Its presence is felt months later. DeLillo's passing acknowledgement of the lurking presence of the Other within one's self is nothing more than an effervescent moment of literary poignancy. Goldberg and Moore note that in trying to read human rights in humanities one is not trying to offer an artistic antidote to war (Goldberg \& Moore, 2013). Representing and reading narratives of atrocity come with the ethical onus of reclaiming not one instant, but acknowledging a vast expanding historical maze of violation that American fiction like Falling Man refuses to perform.

\section{References}

Anker, E. S. (2011). Allegories of Falling and the 9/11 Novel. American Literary History, 23(3), 463-482.

Anker, E. S. (2013). Fictions of Dignity: Embodying Human Rights in World Literature. Ithaka and London: Cornell University Press.

Baer, U. (2002). Spectral Evidence: The photography of Trauma. Cambridge, MA: MIT Press.

Banita, G. (2012). Plotting Justice: Narrative Ethics and Literary Culture after 9/11. Lincoln \& London: University of Nebraska Press.

Caruth, C. (1996). Unclaimed Experience: Trauma, Narrative and History. Baltimore: John Hopkins University Press.

Chakravorty, S. G. (2004). Terror: A Speech after 9-11. Boundary 2. 31(2).

Chow, R. (2006). The Age of the World Target: Self-Referentiality in War, Theory, and Comparative Work. Durham, NC: Duke University Press.

DeLillo, D. (2008). Falling Man: A Novel. London: Picador.

Gana, N. (2008). Reel Violence: Paradise Now and the Collapse of the Spectacle. Comparative Studies of South Asia, Africa and the Middle East, 28(1), 20-37.

Hirsch, M. (2012). The Generation of Postmemory: Writing and Visual Culture After the Holocaust. New York: Columbia University Press.

Goldberg, E. S., \& Moore, A. S. (2013). Mediations on a Fractured Terrain: Human rights and Literature. College Literature: A Journal of Critical Literary Studies, 40(3), 15-37.

Sontag, S. (2003). Regarding the Pain of Others. New York: Picador 